\title{
El fracaso de los programas de ajuste estructural en América Latina
}

\author{
Joaquín Arriola Palomares
}

Hace diez anos se produjo una inflexión histórica en América Lalina, cuando la suspensión de pagos del gobierno de México desencadenó la crisis de la deuda. Diez anos es un período de liempo suficiente para determinar si la medicina aplicada ha sido suficientemente efectiva en resolver la crisis. Bajo la égida del Fondo Monetario Internacional, el Banco Mundial y el Banco Interamericano de Desarrollo, la mayoría de los paises se vieron obligados a adoptar politicas de estabilización y Programas de Ajuste Eslructural (PAE), y aquellos que se negaron a hacerlo, fueron sulicientemente presionados para caer en el caos y en definitiva en programas de ajuste aun más severos como lestimonian Perú o Nicaragua.

La mayoría de los países de América Latina se encuentra actualmente implementando programas de ajuste estruclural: Venezuela, Argentina, México, Colombia, Unuguay, Perú, Guyana, y la mayoria de los países centroamericanos, tienen sus polílicas económicas amarradas a los dictámenes del Banco Mundial y el Fondo Monetario Inlernacional. Algunos palses, como Chile, Costa Rica y Bolivia, han aplicado ya en su práctica integralidad las políticas de ajusle. Tan solo Brasil, Paraguay y Ecuador tienen poco avanzada la puesta en marcha de las políticas de ajuste, 10 cual responde bien a resistencias internas más exitosas que en otros palses de la región, bien al ensayo de políticas alternativas al ajuste orientado por el FMI y el BM, O a una combinación de ambos factores. 


\section{El ajuste estructural: la nueva estrategla del capltal}

¿Cuales han sido las principales consecuencias de los programas de ajuste estructural? Para interpretar los datos de la situación, hay que entender previamente que significan los PAE.

La crisis estructural de los años 70 y 80 conoce dos etapas bien diferenciadas. En la primera, los componentes de la crisis se van desarrollando sin que los gobiernos ni el capital encuentren las respuestas adecuadas:

-el aumento de los precios de las materias primas -principalmente el petróleo- se pudo dar luego que los gobiernos exportadores del lercer mundo nacionalizaran sus recursos nalurales;

- los incremenlos salariales logrados por los trabajadores en la mayoría de los países desarrollados elevaron los cosles unitarios, reduciendo la tasa de ganancia o rentabilidad del capital;

-el papel regulador del Estado requería ingresos fiscales cada vez más elevados para subvencionar la lasa de ganancia del capital en un contexlo de rentabilidad descendente y para sufragar los gastos de la prolección social, cuando el desempleo empezaba a aumentar dramáticamente.

Estos mecanismos contribuyeron a acelerar la caida de la tasa de ganancias, y con ello a desacelerar la inversión y desencadenar la crisis de acumulación.

El capilal lardó varios años en encontrar la respuesta integral -política y económica, pero también sociał para recuperar su hegemonía y recomponer la tasa de ganancia. Al final encontró la respuesta en el monetarismo: los gobiernos conservadores de Reagan y Tatcher realizaron en sus países una masiva redistribución de riqueza desde los pobres hacia los ricos, y de los trabajadores hacia el capital, y esta tendencia económico-política, llamada neoliberalismo, se impuso en lodo el mundo capilalista desarrollado, pues la compelencia obligada a lodos los gobiernos, conservadores o socialdemócratas, a crear las condiciones para un relanzamiento de la acumulación de sus capitales nacionales.

La nueva hegemonia del capital requería encontrar unos chivos expialorios de la crisis que sacudia a las sociedades desarrolladas. Como culpables oficiales fueron designados por la lógica neoliberal los trabajadores y los paises del lercer mundo, especialmente los semiindustrializados y los productores de petróleo. Aquellos, eran responsables de la caída de la rentabilidad de las empresas, pues apoyándose en el poder del sindicato en las empresas y en la situación de virtual 
pleno empleo, habrian impuesto al capital unos incrementos salariales que habrian reducido excesivamenle la ganancia de los capitalistas, tomenlando la desconlianza de éstos en la rentabilidad de las inversiones y provocando por tanlo la caída de éslas y el estancamiento. Además, sus demandas excesivas al Eslado en materia de gasto público, alentadas por unos políticos populistas, contribuyeron a minar las ganancias del capital por la vía de los impueslos, y en último término, provocaron la crisis fiscal del Estado.

Los paises del tercer mundo exportadores de manufacturas se convirtieron en una nueva fuente de competencia para la producción de los países desarrollados, y se convirtieron en el principal argumento para justilicar la caida de la producción en diversas ramas en los países ricos: siderurgia, construcción naval, automóvil y textil, donde los trabajadores veian desaparecer sus puestos de trabajo en un proceso de racionalización del capital que se justilicaba con las relerencias a la competencia de los "nuevos paises industrializados". Los exporladores de petróleo, especialmenle los paises árabes, funcionaron durante varios anos como chivos expiatorios para los males de las economias desarrolladas, desviando la atención de las contradicciones internas del propio sistema.

El ataque contra los trabajadores, su fuerza organizada en las empresas y en la sociedad y su participación en la renta nacional, más o menos adornado, forma parle del dogma neoliberal, se encuentra en la base de las políticas de flexibilización y desregulación del mercado de trabajo en todos los paises desarrollados, para debilitar la capacidad de los trabajadores de negociar su tasa de explotación, lo cual en algunos casos adopla la forma de ataques directos al sindicalismo como en la Inglaterra de Margarel Tatcher, y en el freno a la expansión de las políticas de gasto público. Asimismo, casi lodos los paises desarrollados aplicaron contrarreformas liscales, orientadas a reducir la presión fiscal sobre las ganancias del capital. El alaque al Estado sirvió además para translerir al mercado delerminadas áreas que socialmente se consideraba eran bienes y servicios que debía suministrar el Estado: en algunos casos, se trató de la introducción de la flexibilidad en los servicios públicos; por ejemplo con la privatización de delerminados servicios, de bienestar social, recogidas de basura y otros. En otros casos, se trataba de aportar nuevos espacios para la valorización del capital, en unas áreas con grandes perspeclivas de expansión, como las comunicaciones, la energía o diversos servicios comunilarios, incluidos los servicios de salud y educativos. 


\section{El ajuste en América Latina: la prlvatización}

Cuando este discurso se Iraslada a América Latina, se encuentra con unas realidades en las cuales los trabajadores asalariados urbanos representan un papel menos relevante en el proceso de acumulación que en los países desarrollados. Esto explica que los programas de ajuste estructural en Latinoamérica pongan gran parte del acento en la situación del sector público: déficit liscal y privalización son los dos grandes objetivos, respectivamente, de las políticas de estabilización y de los programas de ajusle.

El ataque al Eslado que se ha producido en América latina durante el úttimo quinquenio ha dejado unas secuelas que tardarán al menos dos generaciones en ser borradas, si es que se aplican de inmediato unas polílicas dilerentes, cosa que no está todavia en la agenda.

Los PAE son la aplicación a América Latina de las polílicas monetarislas dominantes en la década de los $\mathbf{8 0}$ en casi todo el mundo capilalista, con sus particularidades: el Estado cumplía en las décadas anteriores un papel fundamental tanto desde el punto de visla del consumo como de la inversión: con su actividad, suplia de alguna manera las deficiencias del proceso de acumulación, es decir, la debilidad del sector capitalista nacional en casi lodos los países de la región. Las privatizaciones han jugado fundamentalmenle en benelicio del capital transnacional, que se está quedando con la mejor parte de los activos empresariales nacionales. En consecuencia, la dependencia de América latina -ese término lan denostado como real, sigue siendo el que mejor define la siluación estructural del continente- se renueva y profundiza por palida doble: el crecienle control transnacional de los procesos de acumulación nacionales en Latinoamérica, se complementa con unos Estados debilitados a tal punto que ni siquiera pueden cumplir las funciones regulalorias minimas en maleria de aporlación de infraesıructuras y reducción del coste de reproducción de la luerza de trabajo (salud y educación fundamentalmente).

Se comprende asi la fragilidad de los proceso democratizadores que recorren América Lalina: son democracias sin Estado, donde otros agenies (Ejércilos, US AID, FMI, Banco Mundial y BID) se encargan de planificar las actividades del sector público, lo que supuestamente correspondería a los designados por votación popular. Los electos son rehenes, cuando no verdaderos cómplices, de quienes disehan el pillaje generalizado al patrimonio público de los paises de América Lalina.

Los PAE han tenido un relativo exito en estabilizar los desequilibrios financieros más importantes, con excepción de la deuda externa: el défi- 
cit fiscal de los gobiernos centrales de América Latina varió de un - $9.2 \%$ del PIB en 1983 hasla un saldo positivo en 1990 y 1991 y de $0,2 \%$ y $1,2 \%$ respectivamente; los precios ponderados pasaron de una variación anual del 109\% en 1983 a un $36 \%$ en 1992 (Perspectivas de la Economía Mundial, mayo 1991, FMI).

\section{Cuadro 1}

Amérlca Latlna: producto Interno bruto por tlpo de gasto (miles de millones de dólares de 1988)

\begin{tabular}{|l|l|l|l|l|l|l|l|l|l|l|}
\hline & 1991 & 1982 & 1983 & 1984 & 1985 & 1986 & 1987 & 1988 & 1989 & 1990 \\
\hline Consumo & 591.6 & 589.9 & 582.1 & 599.7 & 613.1 & 632.6 & 639.9 & 639 & 649.8 & 651 \\
\hline Invers. & 220.3 & 190.5 & 143.5 & 150.1 & 158.3 & 170.7 & 179.6 & 180.3 & 169.2 & 163.2 \\
\hline $\begin{array}{l}\text { Expor- } \\
\text { laciones }\end{array}$ & 90.3 & 91.3 & 97.8 & 105.2 & 109 & 108.4 & 117.1 & 126.2 & 133.5 & 141 \\
\hline $\begin{array}{l}\text { Importa- } \\
\text { ciones }\end{array}$ & 134.7 & 111.3 & 84.4 & 88.6 & 87.7 & 93 & 97.1 & 104.8 & 107.2 & 111.2 \\
\hline C+1+X & 902.2 & 870.7 & 623.4 & 655 & 890.4 & 911.7 & 936.6 & 945.5 & 952.5 & 955.2 \\
\hline $\begin{array}{l}\text { Consu- } \\
\text { mo\% }\end{array}$ & 65.6 & 67.6 & 70.7 & 70.1 & 69.6 & 69.4 & 68.3 & 67.6 & 68.2 & 68.2 \\
\hline $\begin{array}{l}\text { Inversion } \\
\%\end{array}$ & 24.4 & 21.9 & 17.4 & 17.6 & 18.0 & 18.7 & 19.2 & 19.1 & 17.6 & 17.1 \\
\hline $\begin{array}{l}\text { Exporta- } \\
\text { ciones \% }\end{array}$ & 10.0 & 10.5 & 11.9 & 12.3 & 12.4 & 11.9 & 12.5 & 13.3 & 14.0 & 14.8 \\
\hline $\begin{array}{l}\text { Importa- } \\
\text { ciones }\end{array}$ & 14.9 & 12.8 & 10.3 & 10.4 & 10.0 & 10.2 & 10.4 & 11.1 & 11.3 & 11.6 \\
\hline
\end{tabular}

Fuente: BID: Informe 1991.

Como contrapartida, las políticas de ajusle están dejando unas secuelas de delerioro estruclural que tardarán varias décadas en ser superadas: el consumo, que creció a una lasa anual de $5.4 \%$ enlre 1960 y 1970 , aumentó al $6 \%$ anual en la década siguiente, trulo en gran medida de los préstamos internacionales, para caer al 1,1\% entre 1981 y 1990 , cuando se desencadenó la crisis de la deuda y el drenaje de fondos hacia los países desarrollados. Tan sólo las exportaciones conlinuaron creciendo a un ritmo del $5 \%$ anual $\left(4,7 \%\right.$ en los ' 70 y $5,8 \%$ en los $\left.{ }^{\prime} 60\right)$, generando un aumento de divisas que en vez de dedicarse a renovar el 
capilal y el proceso de acumulación, se destinó al pago de la deuda externa. El esfuerzo externo de América Latina se enlenderá mejor si se considera que la relación real de intercambio tuvo una variación anual promedio del -3\% entre 1983 y 1992, es decir, que cada año tenía que exportar en promedio un $3 \%$ más, solo para tener los mismos ingresos en divisas. Las importaciones disminuyeron en la década pasada a una tasa anual del $-1,1 \%$ (frente a un aumento del $8,2 \%$ en los 70 y $5,8 \%$ en los 60), y la inversión, que crecía en las décadas anteriores a una lasa del $7,4 \%$ anual, descendió entre 1981 y 1990 a un ritmo del $-3,2 \%$ al año.

\section{Cuadro 2}

Amérlca Latina: formación bruta de capltal fijo

a precios constantes (millones de dólares de 1980)

\begin{tabular}{|l|c|c|c|c|c|}
\hline & FBCF & $\begin{array}{c}\text { FBCF } \\
\text { construcción }\end{array}$ & $\begin{array}{c}\text { FBCF } \\
\text { máquina }\end{array}$ & $\begin{array}{c}\text { variación } \\
\text { anual } \\
\text { FBCF }\end{array}$ & $\begin{array}{c}\text { variación } \\
\text { anual } \\
\text { FBCF } \\
\text { máquina }\end{array}$ \\
\hline 1970 & 76412.9 & 48279.0 & 28133.9 & 48.6 & 44.2 \\
1971 & 82450.4 & 51581.9 & 30868.5 & 52.4 & 48.5 \\
1972 & 89700.4 & 55632.8 & 34067.6 & 57.0 & 53.5 \\
1973 & 100481.9 & 60756.1 & 39725.8 & 63.9 & 62.4 \\
1974 & 110120.7 & 65276.4 & 44844.3 & 70.0 & 70.5 \\
1975 & 119117.4 & 69329.6 & 49787.8 & 75.7 & 78.2 \\
1976 & 127038.1 & 75801.6 & 51236.5 & 80.8 & 80.5 \\
1977 & 132824.9 & 80189.7 & 52635.2 & 84.5 & 82.7 \\
1978 & 138933.4 & 85073.6 & 53859.8 & 88.3 & 84.6 \\
1979 & 145616.4 & 88132.7 & 57483.7 & 92.6 & 90.3 \\
1980 & 157266.4 & 93638.0 & 63628.4 & 100.0 & 100.0 \\
1981 & 156240.4 & 94170.9 & 62069.5 & 99.3 & 97.5 \\
1982 & 136959.7 & 87825.0 & 49134.7 & 87.1 & 77.2 \\
1983 & 110180.2 & 74129.2 & 36051.0 & 70.1 & 56.7 \\
1984 & 109520.4 & 71588.6 & 37931.8 & 69.6 & 59.6 \\
1985 & 115683.1 & 74631.5 & 41051.6 & 73.6 & 64.5 \\
1986 & 124810.0 & 79738.1 & 45071.9 & 79.4 & 70.8 \\
1987 & 127989.8 & 82391.1 & 45598.7 & 81.4 & 71.7 \\
1988 & 126920.9 & 79648.3 & 47272.6 & 80.7 & 74.3 \\
\hline
\end{tabular}

Fuente: Cuadernos esladísticos de la CEPAL núm. 15, 1991. 


\section{Objetivo de la privatización}

Durante la década de los ' $\mathrm{BO}$, América Latina sufrió por parlida triple la dependencia respeclo al capital transnacional: el servicio de la deuda se convirtió en una pesada losa que, cuanlo más se pagaba, más pesaba; en 1983 la deuda total era de 344,5 mil millones de dólares, y en 1992 de 398,4 mil millones de dólares; en estos mismos ańos América Lalina pagó 531,5 mil millones de dólares en conceplo de servicio de la deuda externa, cuatro quinlas partes en concepto de inlereses.

-Al mismo liempo, los pagos netos por remisión de ganancias de inversiones extranjeras representaron en los mismos diez años 344,2 mil millones de dólares.

- Las nuevas inversiones extranjeras están orientadas en su mayor parte a la adquisición de los activos públicos en proceso de privatización en lodo el subcontinente, con la excepción de las inversiones en actividades de maquila o ensamblaje, cuyos efectos externos en maleria de aprendizaje tecnológico y demanda interna es mínima.

\section{Cuadro 3}

América Latina: transacclones por cuenta corriente (miles de millones de dólares corrientes)

\begin{tabular}{|c|c|c|c|c|c|c|c|c|c|c|}
\hline & 1983 & 1984 & 1985 & 1986 & 1987 & 1988 & 1989 & 1990 & 1991 & 1992 \\
\hline $\begin{array}{l}\text { Balanza } \\
\text { Comercial } \\
\text { (lob) }\end{array}$ & 29.3 & 37,7 & 33,1 & 16.5 & 19.1 & 23.1 & 29,2 & 26,5 & 21.8 & 20.6 \\
\hline $\begin{array}{l}\text { Servicio } \\
\text { de la deuda }\end{array}$ & 50,4 & 55.1 & 51.6 & 43,2 & 49,0 & 64,8 & 50,1 & 48,1 & 55,4 & 57.8 \\
\hline $\begin{array}{l}\text { Pago de } \\
\text { intereses }\end{array}$ & 40,5 & 44,3 & 41,5 & 36,9 & 34,1 & 37,4 & 40,9 & 40,4 & 35,9 & 35,2 \\
\hline $\begin{array}{l}\text { Renta de } \\
\text { inversiones }\end{array}$ & -30.3 & $-31,6$ & $-31,8$ & -31.1 & $-32,6$ & $-35,8$ & $-39,8$ & $-39,3$ & $-36,3$ & $-35,6$ \\
\hline
\end{tabular}

Fuente: elaboración propia a partir de: Perspectivas de la Economía Mundial mayo 1991, FMI (varios cuadros).

1985 es la fecha del inicio general de la privatización lalinoamericana, aunque antes se conocieron en algunos paises experiencia que adelantaban la gran ola privalizadora de la segunda milad de la década pasada: Chile (1976), Venezuela (1981), México (1983) y Jamaica (1985).

Pocos gobiernos declaran tan abiertamente como el de El Salvador 
(solo encontramos un discurso semejante en Chile durante la dicladura militar) que su objetivo es "reducir el tamano del gobierno" para lo cual planlea como medida "realizar como mínimo cualro privatizaciones de gran relevancia económica" para 1991 (GAES, Informe Anual 1990, matriz de lineamientos de polílica económica, pp. 207-208). Curiosamente, la privatización aparecía enlre los objetivos del programa monetario y tinanciero del BCR para 1992 como una acción que deberá contribuir a la reducción del déficit fiscal y al aumento del ahorro corriente (medidas Nos. 9 ("impulsar las medidas para reducir el tamano del sector público") y 10 ("acelerar la privalización de las empresas públicas seleccionadas"). También hay pocos paises en los que las actividades productivas en manos del Estado son tan escasas como en El Salvador. Por tanto, la ola privatizadora tiene en El Salvador un carácler más ideológico, más político, menos racional, menos modernizante, menos constrefiido por las presiones del FMl/BM/deuda externa, que en la mayoria de los paises de América Lalina.

\section{La politica flscal en el contexto del PAE en EI Salvador}

Uno de los componenles esenciales de las políticas de ajuste eslructural de la reforma fiscal.

La reforma liscal no se puede interprelar tomando cada impuesto de forma aislada, ni siquiera analizando lodo el sislema impositivo como un conjunlo cerrado, pues la reforma de los INGRESOS está intimamente conectada con la reforma del GASTO: son parte del mismo paquele, cuya lógica sólo se puede enlender viendo ambas caras de la reforma.

El tratamienlo de la cuestión fiscal en los paises desarrollados no es ajena a estos cambios sociales y políticos. Entre los antos 1975 y 1981, la concepción dominante entre los economistas va a modificarse profundamente. Antes de esa fecha, en un período de crecimiento más o menos eslable, el aumento del gaslo público, dedicado a crear infraestructuras y gasto social, se veía como positivo, favorecedor de las condiciones de valorización del capilal privado. A partir de 1975, el crecimiento se reduce, y el Estado se dedica cada vez más a gaslos improductivos: pago de pensiones y subsidios a los desempleados y a actividades productivas como las comunicaciones, que se vuelven un objetivo tentador para el capital privado, necesitado de nuevos espacios de valorización ante la crisis de muchas actividades tradicionales (siderurgia, construcción naval, automóvil, elc.).

Esta nueva situación significará un cambio en la lógica liscal: los impueslos directos, que antes se veian como lavorecedores de la redis- 
tribución de la riqueza, ceden terreno, y ahora se consideran desalentadores para la inversión y el crecimiento. Los impuestos indirectos, sobre todo los impuestos al consumo, se verán ahora más positivamenle, porque se considera que inciden menos negativamente sobre el ahorro y la inversión.

En América Latina, los agentes internacionales tienen un papel preponderanle tanto en la orientación como en la implementación de los PAE: los organismos multilaterales de financiación (especialmente FMI, Banco Mundial y BID) se convierten en disef́adores de la política económica en sustitución de los gobiernos, y las multinacionales - públicas y privadas- presionan por la privatización del patrimonio social y empresarial de los Estados.

Estas presiones se hacen senlir también en materia fiscal. En este caso, las recomendaciones del Banco Mundial van orientadas a incremenlar la recaudación fiscal, cuyo bajo nivel es laclor de ineficiencia en la gestión gubernamental. El IVA es el impuesto ideal para la lógica del ajuste: impuesto al consumo, que no pagan las empresas sino los ciudadanos consumidores, y cuya recaudación facilila el control fiscal de las aclividades económicas (el Estado neoliberalizado es mucho más conlrolador que el anterior).

La relorma fiscal que se está llevando a cabo en El Salvador es la aplicación directa, sin adaplación a las condiciones reales del pais, de la política liscal neoliberal. Los problemas fiscales del país derivan de una ESCASA carga tributaria, una elevada evasión, un excesivo peso de los impuestos indireclos, y el reducido número de contribuyentes polenciales direclos. Para estos problemas, no hay análisis ni respueslas, ni teóricas ni prácticas, en los documentos del gobierno, de ARENA o de la AID.

EI IVA es generaimente un impueslo que se aplica para pasar de una estructura impositiva centrada en la renta a una centrada fundamentalmente en el consumo. Pero el impuesto que viene a sustiluir -el Timbre- ya era un impuesto al consumo. Como el consumo constituye una base fiscal más reducida que la renta, es evidenle que los acluales gobernantes del país no están pensando en resolver los problemas reales de la estructura tributaria salvadorefía. La óptica de clase con la que se está realizando la reforma fiscal responde a los intereses de los sectores dominantes del gran capital. Además de la implantación del IVA, el gobierno ha realizado otras medidas de gran importancia: se han reducido a menos de la mitad las lasas imposilivas en el impuesto de la renta, especialmente las de la personas con elevados ingresos. A las personas juridicas (impuesto de sociedades), se ha reducido la lasa 
para aquellas empresas de más de 900.000 colones, y se ha elevado la tasa a las empresas con una cifra de negocios inlerior a esa cantidad. Es decir, se han reducido las tasas de 330 grandes empresas, y a cambio se le han incrementado a 9000 medianas y pequenas empresas. Además, el GOES cedió a las presiones del gran capital, y no aprobó la inclusión en el código penal del delito fiscal.

La lectura más inmediata que se deduce de eslo es que el GOES espera incrementar la recaudación fiscal a través del IVA a partir de la fiscalización de las medianas y grandes empresas, pero que esle mayor control no significará una mayor recaudación del impuesto a la renta de las personas lísicas y jurídicas aplicado a las grandes forlunas, pues el mayor control se compensa con la enorme reducción de las lasas. Aun así, se facilita siempre la evasión al no existir el delito fiscal. Lo único que se le va a pedir a las empresas, por tanlo, es que recauden el IVA -que no pagan ellas, sino los consumidores.

\section{Las presiones inflacionistas}

La reforma fiscal contribuirá a incrementar los ingresos fiscales del Estado, pero siempre en una medida insuficiente para lo requerido por una política de desarrollo efectivo. La estructura fiscal, que responde a un diseño coherentemente capilalista de la política fiscal, no va a reducir en absoluto la incoherencia económica y social. Cuando solamente el $40 \%$ de la riqueza nacional corresponde a los trabajadores asalariados, Irente a un $60 \%$ de rentas no salariales ( $30 \%$ de utilidades), la estructura fiscal, si descansa sobre el consumo, restringe la base fiscal a poco más de la milad de la riqueza nacional, quedando casi el $50 \%$ del PIB fuera del alcance del lisco (pues las rentas que se transforman en consumo son las salariales, y las no salariales en gran medida se ahorran, se invierten o se consumen en el ex(erior).

El incremento de los precios experimenlado en los últimos meses del afoo es principalmente consecuencia de los empresarios distribuidores, que lograron una ganancia especulaliva incrementando los precios, cuando teóricamente el impacto marginal del IVA sobre los cosles iba a ser mínimo, cuando no negativo. La decisión del BCR de retirar liquidez del sistema es una medida propia de la ortodoxia neoliberal para reducir el incremento de los precios, pero el coste que lleva aparejado en términos de fomentar la recesión será mucho mayor que el beneficio de contención de los incremenlos de precios, pues el origen de la aceleración de la inflación no se encuentra en un exceso de liquidez, sino en el elevado grado de colusión presente en los mercados de bienes y servi- 
cios, en el control oligopólico de los precios por parte de los oferentes.

La reforma fiscal ha sido por tanto un rolundo FRACASO, al reducir los ingresos por impuestos direclos y por los impueslos sobre el comercio exterior, al seguir facilitando un elevadísimo fraude liscal, y al haber implantado un impuesto que, al no haber actuado previamente sobre las estructuras distributivas, ha contribuido a borrar el único logro en materia de búsqueda de equilibrios que habia logrado hasla ahora el programa neoliberal, que era el conlrol de la inllación. Cuando el ciclo de las políticas neoliberales se está cerrando en todo el mundo (tanto el gobiemo conservador brilánico, como el nuevo presidente de los EE.UU., como la agencia olicial de cooperación japoneses... es a muy diversos niveles institucionales que se propone de nuevo políticas de incremento del gasto público y polílicas secloriales de fomento), en El Salvador, la irresponsable conlrarreforma fiscal obliga a diseñar un presupuesto para el año '93 con profundas características contractivas, to cual dificulta la Iransición desde una situación de guerra a una siluación de acumulación acelerada y mejora del bienestar social.

\section{El tracaso del neollberalismo en Amérlca Latina}

Los PAE han provocado un verdadero descalabro económico y social en América Latina. Uno de los indicadores económicos más relevantes, la tasa de inversión, muestra que la inversión se situa en unos niveles muy por debajo del mínimo requerido para una acumulación sostenida, y en paises como El Salvador, ni siquiera alcanza los niveles requeridos para hacer frente a la reposición del capilal y a la obsolescencia por cambio tecnológico, y con los programas de ajuste no ha mejorado en absoluto, sino que incluso se ha deleriorado aún más. EI PAE ha sido incapaz de modificar esta tendencia hislórico-estructural a la subinversión, situación delerminante en el ritmo y la calidad de la acumulación.

Las causas de esle fracaso son de diversa indole: por una parte, no hay que desconsiderar el hecho de que el Banco Mundial no estaba preparado técnica ni políticamente para asumir la larea de disefiar y promover la aplicación de verdaderos PAE, cuya aplicación en América Latina está casi sin excepción subordinada a los planes de estabilización del FMI.

Por otro lado, su implementación respondio más a razones políticas de dentro y luera de los países (especialmente la necesidad de mantener la solvencia del sistema linanciero inlernacional y abrir nuevos espacios a la valorización del capilal multinacional) que a una verdadera estrategia de desarrollo capilalista. 


\section{Cuadro 4 \\ Formación bruta de capital 11Jo en El Salvador 1970-1991}

\begin{tabular}{|c|c|c|c|c|}
\hline AÑO & FBCF/PIB & Ipriv/PIB & Ipub/PIB & Ipriv/Ipub \\
\hline 1970 & 10.7 & 8.4 & 2.3 & 78.5 \\
\hline 1971 & 11.2 & 8.3 & 2.9 & 74.1 \\
\hline 1972 & 14.1 & 10.1 & 4 & 71.6 \\
\hline 1973 & 12.4 & 8.8 & 3.6 & 71.0 \\
\hline 1974 & 14.2 & 9.5 & 4.7 & 66.9 \\
\hline 1975 & 23 & 15 & 8 & 65.2 \\
\hline 1976 & 20.1 & 13.9 & 6.2 & 69.2 \\
\hline 1977 & 21.2 & 13.9 & 5.8 & 65.6 \\
\hline 1978 & 21.4 & 15.6 & 6.1 & 72.9 \\
\hline 1979 & 17.6 & 11.5 & 4.6 & 65.3 \\
\hline 1980 & 13.5 & 6.4 & 7.1 & 47.4 \\
\hline 1981 & 13.5 & 6.2 & 7.3 & 45.9 \\
\hline 1982 & 12.6 & 6.5 & 6.1 & 51.6 \\
\hline 1983 & 11.6 & 7 & 4.6 & 60.3 \\
\hline 1984 & 11.5 & 7.6 & 3.9 & 66.1 \\
\hline 1985 & 12 & 8.7 & 3.3 & 72.5 \\
\hline 1986 & 13.1 & 10.6 & 2.5 & 80.9 \\
\hline 1987 & 13.6 & 10.7 & 2.9 & 78.7 \\
\hline 1988 & 12.5 & 9.5 & 3 & 76.0 \\
\hline 1989 & 12.9 & 10 & 2.9 & 77.5 \\
\hline 1990 & 11.8 & 9.5 & 2.3 & 80.5 \\
\hline 1991 & 13.8 & 10.9 & 2.9 & 79.1 \\
\hline
\end{tabular}

Fuente: International Finance Corporation, Banco Mundial 1991. 
En consecuencia, los PAE se han visto reducidos a la apertura externa y a la privalización. Las consecuencias principales son la desestabilización de los sistemas nacionales de precios relativos (que ya estaban en crisis por la carga de la deuda) y la subordinación de la asignación de recursos a un sistema de precios sobredelerminado por los precios mundiales, que corresponden a las condiciones productivas, distributivas y tecnológicas de los paises dominantes. Pero el efecto más negativo ha venido desde la reducción ideológica y tinanciera del papel del Eslado. Los programas de ajusle estructural implementados en los paises de la OCDE requirieron una mayor y no una menor participación del Estado en la economía. Si bien se abrieron diversos espacios económicos nuevos al capital, hasta entonces patrimonio de la aclividad estatal (industrias de la inlormación y la comunicación, salud e infraestructuras), y se redujo la participación directa del Eslado en la producción de mercancias, ello no significó una reducción de la actividad estatal -que por el contrario representó una parte crecienle del gaslo en casi todos los paises de la OCDE durante los afios ' 80 . Ello es asi porque, además del manlenimiento de los sistemas de protección social, el ajusle estructural implicaba nuevas inversiones en lormación y capacitación de la fuerza de trabajo, invesligación y desarrollo tecnológico a largo plazo, nuevas formas de financiamiento de la industria (reconversión industrial), la reforma del sistema linanciero (diferente a su privalización) y la reforma de la Adminisıración (diferente a la reducción del Estado o del "gobierno"). Todo lo cual exigió y exige una enorme cantidad de recursos públicos. Si bien es cierto que en los paises de la OCDE se recurrió a la privalización parcial o tolal de diversas actividades como medida para mejorar la competencia, trasladar el mismo planteamiento a América Latina se ha demostrado una forma muy dafina de dependencia inlelectual: en América Latina $-y$ mucho más en Centroamérica- el Estado no ocupa el espacio del mercado, sencillamente porque el mercado no eslá desarrollado o existe de forma limitada y polarizada (mercado trunco, por usar una expresión cepalina) ya que la mayoria de la población carece de los ingresos necesarios para constituirse en demanda solvente. La reducción del Estado solo ha contribuido a profundizar la recesión económica y la pobreza social, paralelamente al mejoramiento de la lasa de ganancia de las multinacionales y el gran capital, que acceden a ocupar los espacios productivos cedidos por el sector público. Sin que esta mayor inlernacionalización y centralización del capital signifiquen en modo alguno un desarrollo de los mercados nacionales.

\section{En busca de alternatlvas}

La hegemonía del neoliberalismo es casi total en América Latina y el 
Caribe. Los espacios para disefiar una estrategia alternativa son escasos, lanto en el mundo político como acadérnico. La CEPAL elaboró recientemente una propuesta alternaliva: "Ajusle con equidad", que sin embargo, no reune los requisitos para conslituirse en un programa alternativo. Sus debilidades principales radican en no entender todavla las mutaciones que están sufriendo los países del área, tanto en la lorma del proceso de acumulación como en las características y expectativas de los agentes presentes.

El retroceso del Estado es una realidad general en América Latina, especialmente en materia de protección social e inversión pública. Sin embargo, el Estado renueva sus funciones de legitimación, con los procesos democrálicos, que se presentan como un marco más adecuado para implemenlar las políticas de ajusle con el consenso de una nueva fracción de clase dominanle, las capas medias articuladas al capital Iransnacional, a las actividades comerciales y a las aclividades del Estado. Una parte importante de la intelectualidad crílica latinoamericana de los años setenta se encuentra integrada de este modo a los circuitos internacionales (salarios indexados en dólares a resguardo de las devaluaciones, viajes aéreos y condiciones de vida poco alectadas por las políticas de ajusle, sea como asesores gubernamentales, funcionarios de agencia multilaterales, consultores independientes 0 articulados a las redes de ONG's-).

Al mismo tiempo, las práclicas Iradicionales de la izquierda, insurrecionales y de lucha armada por un lado, $y$ las reivindicativas urbanas por otro, han agolado su eficacia en el nuevo contexto. La lucha armada se agoló ante unas fuerzas armadas que en las dos décadas pasadas se han translormado en muchos países en uno de los sectores más dinámicos y modernos: su elicacia se ha vislo incremenlada en la lucha contra las insurgencias de diverso tipo, además de extender sus actividades al campo económico. En Gualemala especialmente, pero lambién en Bolivia, Argentina o Brasil, la fuerza armada juega un rol preponderante en diversos ámbilos de la economía: sector financiero, industria militar y aeronáulica, comercialización e incluso en actividades de contrabando, relativamente imporlantes en países económicamente deprimidos. Por otro lado, la transición de los regímenes militares de los '70 a las democracias poco participativas de los ' 80 ha mantenido a los ejércilos en un papel político activo - se habla de "democracias vigiladas", en el sentido de que las posibilidades de la transformación social por la vía de las elecciones populares encuentra su límite inicial alli donde lo eslablece la Fuerza Armada.

Al mismo liempo, la década de los ' 80 ha conocido una importanle 
translormación en la estructura de las sociedades lalinoamericanas. Asistimos a la emergencia de nuevos actores sociales y políticos, por lo general como consecuencia no planificada de los PAE. La población urbana, el $57,2 \%$ del 1otal en 1970 , pasó a ser el $64,9 \%$ en 1980 , y es hoy del $72 \%$. Este enorme incremento cuanlitativo ha transtormado el lipo de problemas que afecta a los paises del subcontinente, en una dimensión que aun no ha sido suficientemente aprehendida en los paises desarrollados, ni por los políticos lalinoamericanos: la contaminación ambiental de las grandes urbes, el desarrollo de las entermedades derivadas de la polación, se combinan con la desforestación acelerada para plantear el problema ecológico con una nueva centralidad política y social. A su vez, las políticas de ajuste han modificado profundamenle el mapa social: el incremento de las actividades intormales en las ciudades se ha visto acompanado del delerioro de las condiciones de Irabajo y del peso numérico y social de la clase obrera y los trabajadores asalariados en general; el aumento de las zonas marginales y el establecimiento en estas de redes de sobrevivencia de uno u otro lipo (por ejermplo la experiencia de Villa EI Salvador en Lima, las ollas populares en Santiago de Chile: aquella un inlento de inserción productiva y desarrollo social, ésla una articulación de la solidaridad en busca de la subsislencia) ha translormado a "los marginales" en un sujeto politico y economico con voz propia ("Nueva Economía Popular", en expresión de Aquiles Monloya), aunque lodavia no sulicienlemente articulado a las práclicas politicas inslitucionales. La experiencia de Brasil, donde se combinan las polílicas sociales de la Iglesia Católica y los esfuerzos organizalivos del partido de los Trabajadores y de la Central Unica de Trabajadores es un caso de análisis y reflexión para toda la izquierda lalinoamericana. El relroceso de la presencia reguladora del Estado se ha visto acompanada de un peso creciente de las Organizaciones No Gubernamentales, que a través de su articulación internacional, ha introducido con renovada fuerza problemálicas tradicionalmente marginadas, como la defensa de los derechos de los ninos, o la lucha feminista.

Nuevos actores sociales, nuevas problemáticas políticas y sociales, que se combinan con una nueva economia: la informalidad urbana ha pasado de constituir una lorma de sobrevivencia a articular redes produclivas y dislributivas que escapan a la lógica de los precios impuesta por el monetarismo, rescalando áreas produclivas enteras o parcialmente al proceso acelerado de centralización del capital que se vive en todas partes. En el agro es especialmente visible esta situación: en Gualemala, las denominadas exportaciones agrícolas no tradicionales se basan en la producción de los indigenas, que son quienes controlan los nuevos cultivos (melones, ajonjoli, verduras etc). De este modo, la bús- 
queda de lormas de supervivencia por parte de los campesinos pobres les ha llevado a ubicarse en producciones con un allo potencial de acumulación. En esta siluación los objetivos inmedialos de la lucha se modifican: ya no se centra en la reivindicación salarial de los campesinos sin tierra, o la defensa del derecho a la tierra, cuanto en combatir a las multinacionales que controlan la distribución y comercialización de sus productos, y la asistencia técnica e insumos (lertilizantes), y lograr el derecho a establecer sus propios canales de comercialización, para retener el excedente -en Guatemala, el solo intenlo de formar una cooperativa agraria representa una automática amenaza de muerte.

Asistencia técnica y acceso al crédito es lambién la bandera de lucha de las cooperativas en El Salvador, en Colombia o en Chile. Las cooperativas se han convertido en un eje fundamental en la implementación de un nuevo proyecto de solidaridad y desarrollo por parte de la izquierda y las fuerzas progresistas en muchas partes de América Latina.

La inmadurez de la allernaliva se refleja en las explosiones de descontento social sin reivindicaciones de largo alcance en Venezuela en 1992 o en la República Dominicana hace pocos años, o el naufragio de los procesos reformistas y de izquierda en Perú y Nicaragua. Las reuniones de partidos políticos de izquierda en febrero en Río de Janeiro y de julio en Managua, las iniciativas de encuenlros sindicales conlinenlales y otras, son un esfuerzo por avanzar en la retlexión común en torno a las alternativas viables.

En ese proyecto, lodavia es una zona oscura la articulación con el Estado, o el papel del capital Iransnacional, o los mecanismos de lijación de precios y asignación de recursos. Las nuevas caraclerísticas y demandas de los sectores populares, el balance de perdedores y ganadores de las políticas de ajuste y los espacios de acluación que se abren en el nuevo ciclo (?) de democracias lalinoamericanas: ¿permitirán una nueva articulación política de grupos y clases sociales en torno a una propuesta a desarrollo eficaz? En la espera, el ajuste estruclural comienza a agotar su tiempo. 

(1) (2)
(3) (4)
(5)
(6) (7)
(B)
(9)
(10)

\begin{tabular}{|c|c|c|c|c|c|c|c|c|c|c|}
\hline Argenlina & $32,2 \quad 86,3$ & $2829-3,2$ & 4,8 & 3,7 & $-12,1$ & 4,7 & 8,6 & 1147 & 58706 & 2314 \\
\hline Bolivia & $7,351,2$ & $880-2,6$ & 6,9 & 2,2 & $-3,3$ & $\cdots$ & & -12 & 5431 & 17 \\
\hline Brasil & $150,374,9$ & $2321-0,8$ & 9,4 & 9,5 & $-2,4$ & .. & & 2794 & 115646 & 2968 \\
\hline Colombia & $33,070,0$ & 1375 & 7,2 & 5,1 & 1,8 & 11,1 & 39,0 & 165 & 16993 & 29 \\
\hline Costa Rica & $3,0 \quad 47,1$ & $1620-0,5$ & 7,9 & 9,3 & $-0,2$ & 19,2 & 18,2 & 121 & 4532 & 19 \\
\hline Chile & $13,285,9$ & $2256 \quad 1,0$ & 9,2 & 2,8 & 0,6 & 25,2 & 17,4 & 109 & 19578 & 26 \\
\hline Ecuador & $10,656,0$ & $1294-0,9$ & 6,51 & 10,4 & $-2,8$ & 14,5 & 7,4 & 80 & 10749 & 49 \\
\hline EI Salvador & $5,3 \quad 44,4$ & $1088-0,9$ & 3,0 & 3,6 & $-0,4$ & 11,9 & 26,2 & 17 & 1760 & 24 \\
\hline Guatemala & $9,239,4$ & $879-1,9$ & 6,6 & 5,2 & $-1,3$ & 10,9 & 20,2 & ЭЭ० & 2577 & 41 \\
\hline HaitI & $6,528,3$ & $353-2,9$ & 4,51 & 11,8 & $-4,2$ & & 17,6 & 10 & $\theta 18$ & 21 \\
\hline Honduras & $5,143,7$ & $925-1,4$ & 9,0 & 6,5 & $-3,0$ & 24,1 & 21,6 & 47 & 3304 & 23 \\
\hline Jamaica & $2,552,3$ & 13020,5 & $6,7-$ & $-9,4$ & 6,2 & 34,8 & 40,3 & -12 & 4305 & 22 \\
\hline México & $80,6 \quad 72,6$ & $1920-0,8$ & 9,1 & 8,6 & $-2,1$ & 21,0 & 31,1 & 2594 & 100752 & 27 \\
\hline Nicaragua & $3,959,8$ & $579-5,6$ & 8,6 & 0,2 & 0,7 & 28,7 & 23,9 & 0 & 8053 & 7485 \\
\hline Panamá & $2,453,4$ & $1960-1,6$ & 13,4 & 3,8 & $-18,1$ & 25,8 & 29,1 & -35 & 5683 & 1 \\
\hline Paraguay & $4,347,5$ & 1450 & 9,21 & 18,2 & 0,3 & 9,3 & 28,8 & 11 & 2497 & 38 \\
\hline Perú & $21,670,2$ & $1629-3,1$ & 2,8 & 8,9 & $-4,3$ & 12,0 & 34,0 & 26 & 18999 & 7482 \\
\hline A. Dominic. & $7,260,4$ & $762-0,6$ & 12,21 & 10,2 & 1,8 & 13,2 & 22,7 & 106 & 3947 & 60 \\
\hline Trinidad T. & $1,269,1$ & $4415-4,1$ & 1,21 & 16,6 & $-10,7$ & 29,8 & 49,9 & 63 & 2040 & 11 \\
\hline Uruguay & $3,1 \quad 85,5$ & $2885-0,5-$ & $-0,4$ & 9,0 & $-8,0$ & 16,2 & 15,3 & 45 & 3826 & 113 \\
\hline Venezuela & $19,790,5$ & $3390-2,3$ & 7,2 & 4,6 & $-7,1$ & 20,3 & 66,9 & 21 & 35427 & 41 \\
\hline Am. Lalina 4 & $431,971,5$ & $2034-1,2$ & 7,4 & 7,4 & $-3,2$ & & & 7578 & & \\
\hline
\end{tabular}

(1): Población total en 1990 (millones); (2): Porcentaje de población urbana en 1990; (3): PIB por habitante en 1988; (4): promedio de tasa de crecimiento anual del PIB por habitanle 1981-1990; (5): Promedio de las tasas de crecimiento anual de la inversión interna brula 1961-1970; 1971-1980; 1981-1990; (6): Gastos totalesdel Gobierno Central como porcentaje del PIB en 1990; (7): Impuestos directos (porcentaje de los ingresos corrientes); (e): Inversión extranjera directa 1988 (millones de dólares); (9): Saldo de la deuda externa total desembolsada 1988 (millones de dólares); (10): IPC de 1990.

Fuente: Informe 1991, BID y Cuadernos Estadísticos de la CEPAL num. 15 